\title{
The Effect of Self-adhesive and Self-etching Resin Cements on the Bond Strength of Nonmetallic Posts in Different Root Thirds
}

${ }^{1}$ Monica Barros da Silva, ${ }^{2}$ Rudys Rodolfo de Jesus Tavarez, ${ }^{3}$ Fernanda Silva de Assis, ${ }^{4}$ Mateus Rodrigues Tonetto
${ }^{5}$ Thiago Soares Porto, ${ }^{6}$ Shilpa H Bhandi, ${ }^{7}$ Omar El-Mowafy, ${ }^{8}$ Sizenando de Toledo Porto Neto, ${ }^{9}$ Matheus Coelho Bandeca

\section{ABSTRACT}

Purpose: The purpose of this study was to evaluate the effect of self-adhesive and self-etching resin cements on the bond strength of nonmetallic posts in different root regions.

Materials and methods: Sixty single-rooted human teeth were decoronated, endodontically treated, post-space prepared, and divided into six groups. Glass-fiber (GF) posts (Exacto, Angelus) and fiber-reinforced composite (FRC) posts (EverStick, StickTeck) were cemented with self-adhesive resin cement (Breeze) (SA) (Pentral Clinical) and self-etching resin cement (Panavia-F) (SE) (Kuraray). Six 1-mm-thick rods were obtained from the cervical $(C)$, middle $(M)$, and apical $(A)$ regions of the roots. The specimens were then subjected to microtensile testing in a special machine (BISCO; Schaumburg, IL, USA) at a crosshead speed of $0.5 \mathrm{~mm} / \mathrm{min}$. Microtensile bond strength data were analyzed with two-way ANOVA and Tukey's tests.

Results: Means (and SD) of the MPa were: GF/SA/C: 14.32 (2.84), GF/SA/M: 10.69 (2.72), GF/SA/A: 6.77 (2.17), GF/SE/C: 11.56 (4.13), GF/SE/M: 6.49 (2.54), GF/SE/A: 3.60 (1.29), FRC/SA/C: 16.89 (2.66), FRC/SA/M: 13.18 (2.19), FRC/SA/A: 8.45 (1.77), FRC/SE/C: 13.69 (3.26), FRC/SE/M: 9.58 (2.23), FRC/SE/A: 5.62 (2.12). The difference among the regions was statistically significant for all groups $(p<0.05)$. The selfadhesive resin cement showed better results than the selfetching resin cement when compared to each post $(p<0.05)$.

\footnotetext{
1,2,9 Department of Dentistry, CEUMA University, São Luis Maranhao, Brazil

${ }^{3,4}$ Department of Postgraduate Program in Integrated Dental Sciences, University of Cuiabá, Mato Grosso, Cuiabá

${ }^{5,8}$ Department of Restorative Dentistry, School of Dentistry UNESP — São Paulo State University, Araraquara, São Pãulo Brazil

${ }^{6}$ Department of Conservative Dentistry and Endodontics MS Ramaiah Dental College and Hospital, Bengaluru, Karnataka India

${ }^{7}$ Department of Restorative Dentistry, University of Toronto Toronto, Canada

Corresponding Author: Matheus Coelho Bandéca, Head Postgraduate Program in Dentistry, Department of Dentistry CEUMA University, Rua Josue Montello, N 01, Renascença São Luis, Maranhão 84035-210, Brazil, e-mail: mbandeca@ gmail.com
}

No statistically significant differences in bond strengths of the resin cements when comparable to each post ( $p>0.05)$.

Conclusion: The bond strength values were significantly affected by the resin cement and the highest values were found for self-adhesive resin cement.

Keywords: Post, Resin cement, Bond strength.

How to cite this article: da Silva MB, de Jesus Tavarez RR, de Assis FS, Tonetto MR, Porto TS, Bhandi SH, El-Mowafy O, de Toledo Porto Neto S, Bandeca MC. The Effect of Self-adhesive and Self-etching Resin Cements on the Bond Strength of Nonmetallic Posts in Different Root Thirds. J Contemp Dent Pract 2015;16(2):147-153.

\section{Source of support: Nil \\ Conflict of interest: None}

\section{INTRODUCTION}

The restoration of nonvital and severely compromised teeth is often performed by using intracanal posts. ${ }^{37,39}$ These prefabricated posts are commonly used to improve the retention of core foundation materials and can be cemented immediately after post space preparation. ${ }^{23}$ Except for ceramics, the nonmetallic posts are preferred over metallic posts because they have a better stress distribution and may help prevent root fractures in the long term. ${ }^{2,4}$ Carbon-fiber posts were the first used for this purpose, followed by glass fiber-, quartz fiber- and fiber-reinforced composite (FRC) posts.

The resin cement used for postcementation is an important factor in the long-term success of a restoration. Adhesive luting is usually recommended for luting the post to the root canal dentine, and it has been demonstrated that different types of bonding systems can be used in combination with different resin cements. Bonding capacity between them may be influenced by contraction stresses induced by polymerization of the resin material. ${ }^{15,28}$ The contraction stresses may occur at the dentin-luting material interface at different regions, depending on the preparation configuration (C-factor). The C-factor is an important consideration in bonding procedures ${ }^{3,14}$ and can be high inside the root because there is little free area to relieve contraction polymerization. ${ }^{8,12}$ The type of post, ${ }^{42}$ the proprieties 
of the luting materials, and the characteristics of the root canal can also be affected. ${ }^{17,26,35}$ Additionally, some authors have demonstrated different bond strengths values in these regions, ${ }^{17}$ whereas other suggested that no differences existed between these regions. ${ }^{18}$

The recent resin cements can be found in selfadhesives or combined with self-etching adhesives. The Breeze resin cement is a self-adhesive system that does not require any pretreatment of the dentin. The application technique for these new materials is simpler than the cementation procedure and is more operator-sensitive than when using total-etching systems. ${ }^{1,11,19,22,44}$

Microtensile, push-out, and pull-out tests have been used to evaluate the bond strength of the luting materialdentine and luting material-post interfaces. ${ }^{7,31,36}$ In pushout tests, the bond strength was evaluated by the retention created not only by the luting agent but also through micro- and macro-retention due to the surface roughness and frictional fit between the two surfaces, respectively. ${ }^{20}$

With the advent of new resin materials in dentistry, it has become important to analyze evolutionally the bond strength though microtensile tests. The purpose of this study was to determine the microtensile bond strength of two non-metallic posts cemented with selfadhesive and self-etching resin cements in different root regions. Stereomicroscopic evaluation of failure modes of the systems was performed and scanning electron microscope (SEM) was used to detect the characteristics of bonding the posts with resin cements. The null hypothesis was that no statistically significant differences in bond strength values would be found between the fiber and FRC posts.

\section{MATERIALS AND METHODS}

Sixty freshly extracted single-rooted human were selected for this study. The crowns were removed at the cement-enamel junction using a low-speed diamond disk (Isomet III; Buehler, Lake Bluff, IL, USA) under constant water cooling.
The root canals were prepared $1 \mathrm{~mm}$ from the apex using rotary nickel-titanium instruments (ProTaper System; Dentsply, Tulsa, OK, USA) and shaping (S1, S2, Sx) and finishing (F1, F2, F3) instruments. The irrigation solution between instrumentations was performed with $2 \mathrm{~mL}$ of $2.5 \%$ sodium hypochlorite. The canals were then rinsed with distilled water, dried with paper points, and obturated with gutta-percha cones using a lateral condensation technique (Dentsply-Herpo) and AH-Plus sealer (Dentsply DeTrey, Konstanz). The specimens were then stored at $37^{\circ} \mathrm{C}$ and $100 \%$ relative humidity for a period of 24 hours.

The appropriate drill supplied by the Exacto post (\#2 drill, Angelus; Londrina, Brazil) was used to a length of $10 \mathrm{~mm}$, leaving 4 to $5 \mathrm{~mm}$ of gutta-percha remaining in the apical third. The drill was replaced every five posts during space preparation. Table 1 shows the features of nonmetallic posts.

The teeth were randomly assigned to four equal groups according to the type of post [glass fiber (GF) and fiber-reinforced composite (FRC)] and resin cement [self-adhesive (SA) and self-etching (SE)].

The luting materials and adhesive application protocols are described in Table 2. Before the application of the resin cement systems, the root canals were irrigated with distilled water and dried using paper points (Dentsply Maillefer). The posts were luted according to the manufacturers' instructions. The cervical region of the roots was sealed with composite resin TPH Spectrum Compule (Dentsply Caulk, Milford, USA) applied in $2 \mathrm{~mm}$ increments. The light-cured materials were light activated with Optilux 501 (Demetron Kerr, Orange, CA, USA). Before each bonding procedure, the power density of the light activation was checked with a digital radiometer. The mean power density of the light activation was 500 $\pm 10 \mathrm{~mW} / \mathrm{cm}^{2}$.

Specimens were fixed with sticky wax into a device adapted to the cutting machine (Isomet III; Buehler, Lake Bluff, IL, USA) and perpendicularly sectioned into approximately 1-mm-thick sections using a low-

Table 1: Features of nonmetallic posts used in this study

\begin{tabular}{|c|c|c|c|c|}
\hline Post & Manufacturer & Post type and design & Post composition & Batch number \\
\hline Exacto post & $\begin{array}{l}\text { Angelus, Londrina, } \\
\text { Brazil }\end{array}$ & $\begin{array}{l}\text { Opaque } \\
\text { Cervical diameter, } 1.8 \mathrm{~mm} \\
\text { Middle diameter, } 1.8 \mathrm{~mm} \\
\text { Apical diameter, } 1.1 \mathrm{~mm}\end{array}$ & $\begin{array}{l}\text { Glass fiber: } 87 \% \text { volume } \\
\text { Epoxy resin: } 13 \% \text { volume } \\
\text { Internal filament: stainless steel }\end{array}$ & 2070814-P3-036 \\
\hline Everstick post & $\begin{array}{l}\text { StickTeck Ltd, } \\
\text { Turku, Finland }\end{array}$ & $\begin{array}{l}\text { Individually formed electrical glass } \\
\text { fiber mean diameter, } 1.5 \mathrm{~mm}\end{array}$ & $\begin{array}{l}\text { Semi-interpenetrating } \\
\text { polymer network of } \\
\text { polymethylmethacrylate, } \\
\text { Mw } 220.000 \text { and } 2.2- \\
\text { bis [4-(2-hydroxy-3- } \\
\text { methacryloxypropoxy) phenyl] } \\
\text { propane }\end{array}$ & 8217 \\
\hline
\end{tabular}


Table 2: Composition of resin cements and adhesive application procedures

\begin{tabular}{|c|c|c|c|c|}
\hline Product name (Manufacturer) & Composition & Dentin pretreatment & $\begin{array}{l}\text { Luting agent } \\
\text { mixing }\end{array}$ & Batch no. \\
\hline $\begin{array}{l}\text { Breeze self-adhesive resin } \\
\text { cement (Pentron Clinical } \\
\text { Technologies, Wallingford, } \\
\text { USA) }\end{array}$ & $\begin{array}{l}\text { BISGMA, UDMA, TEGDMA, HEMA, \& 4-MET } \\
\text { resins, silane-treated, bariumborosilicate } \\
\text { glasses, }{ }^{*} \text { silica with initiators, stabilizers } \\
\text { and UV absorber, organic and/or inorganic } \\
\text { pigments, opacifiersa }\end{array}$ & No pretreatment & $\begin{array}{l}\text { Dispense the } \\
\text { cement, light cure } \\
\text { for } 1 \mathrm{~s} \text { from each } \\
\text { side after removal } \\
\text { of excess cement }\end{array}$ & 161489 \\
\hline \multirow{5}{*}{$\begin{array}{l}\text { Panavia F } 2.0 \text { dual cure resin } \\
\text { cement (Kuraray, Osaka, } \\
\text { Japan) }\end{array}$} & $\begin{array}{l}\text { Primer A: HEMA, 10-MDP, 5-NMSA, water, } \\
\text { accelerator }^{a}\end{array}$ & \multirow{5}{*}{$\begin{array}{l}\text { Mix one drop of } \\
\text { each ED Primer } \\
\text { liquids } A \text { and } B \text { for } \\
5 \text { seconds, apply } \\
\text { undisturbed for } 30 \\
\text { seconds, air-dry } \\
\text { gently }\end{array}$} & \multirow{5}{*}{$\begin{array}{l}\text { Mix paste } A \text { and } \\
B \text { for } 20 \text { seconds, } \\
\text { light cure for } 20 \\
\text { seconds from } \\
\text { each side after } \\
\text { removal excess } \\
\text { cement, apply } \\
\text { oxyguard for } \\
3 \text { minutes }\end{array}$} & 00243B \\
\hline & Primer B: 5-NMSA, water, sodium benzene ${ }^{a}$ & & & 00121B \\
\hline & $\begin{array}{l}\text { Paste A: 10-MDP, 5-NMSA, silica, } \\
\text { dimethacrylate monomer, photo-initiator, } \\
\text { accelerator }^{a}\end{array}$ & & & 00265B \\
\hline & $\begin{array}{l}\text { Paste B: barium glass, sodium fluoride, } \\
\text { dimethacrylate monomer, } \mathrm{BPO}^{\mathrm{a}}\end{array}$ & & & 00043B \\
\hline & $\begin{array}{l}\text { Oxiguard II: glycerol, polyethyleneglycol, } \\
\text { initiators, accelerators, dyes, others }{ }^{\mathrm{a}}\end{array}$ & & & 00564B \\
\hline
\end{tabular}

${ }^{*}$ Contains a small amount of aluminum oxide; HEMA: 2-hydroxyethyl methacrylate; MDP: 10-methacryloyloxydecyl dihdrogen phosphate; 5-NMSA: N-Methacryloyl 5-aminosalicylic acid. ${ }^{a}$ Composition and $\mathrm{pH}$ values according to the manufacturers

speed diamond disk under constant water cooling. This procedure resulted in six serial slices for each root.

The slices of 10 specimens from each group were trimmed using a cylindrical diamond burr (\#1090, KGSorensen, Barueri, SP, Brazil) under water cooling in the proximal surfaces until the post was touched.

A digital caliper (Deigimatic Caliper, Mitutoyo, Kawasaki, Japan) with $0.01 \mathrm{~mm}$ precision was used to measure the thickness of each slice. Specimen sections were attached into a device (Bisco Inc.) with cyanoacrylate glue (Zapit; Dental Ventures of America Inc, Corona, CA, USA), which were then mounted on a strength tester (Bisco, Inc., Schaumburg, IL, USA) and loaded in tension at a speed of $0.5 \mathrm{~mm} / \mathrm{min}$ until failure. The failure loads were recorded in $\mathrm{N}$, and microtensile bond strength was calculated in MPa as follows in Figure 1.

The bond strength data obtained was submitted to two-way ANOVA and was used to compare variables (post/cement and root third). Post-hoc tests were conducted using a Tukey's multiple comparison test at $p<0.05$. The slices were examined under a $25 \times$ stereomicroscope and failure modes were classified into five types, adapted from the classification by Perdigão et al: ${ }^{34}$ (1) adhesion between post and resin cement, (2) mixed with resin cement visible around the post, (3) adhesion between resin cement and root canal, and (4) cohesive in dentin.

One specimen from each group was used for scanning electron microscope observations of the dentin cement and post-cement interfaces at a magnification of 300x.

\section{RESULTS}

Statistical analysis indicated that the types of resin cement and the types of posts, as well as the different root canal thirds, significantly affected the bond strength values $(p<0.05)$. However, there is no interaction between them $(p=0.7604)$ (Table 3$)$. The bond strength values

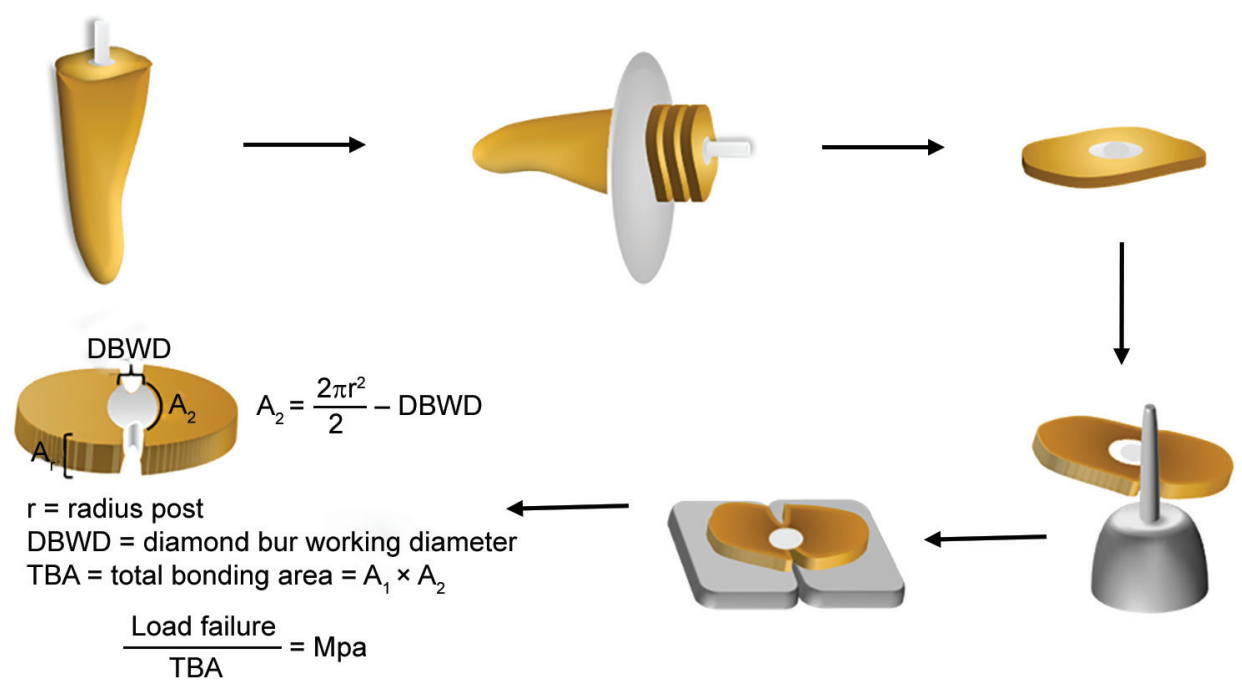

Fig. 1: Schematic of the experimental design 
Table 3: Two-way analysis of variance for cements/posts and thirds

\begin{tabular}{llllll}
\hline Variable (source) & $d f$ & Sum of squares & Mean squares & $F$ & $p$-value \\
\hline Thirds & 2 & 2562 & 1281 & 0.56 & $0.7604^{*}$ \\
Cements/posts & 3 & 975.8 & 325.3 & 48.36 & $<0.0001^{*}$ \\
Interaction & 6 & 22.68 & 3.779 & 190.42 & $<0.0001^{*}$ \\
Residual & 288 & 1534 & 6.726 & & \\
\hline
\end{tabular}

*Significantly different at $p<0.05$

Table 4: Mean push-out bond strength $(\mathrm{MPa}) \pm \mathrm{SD}$ for experimental groups according to the thirds

\begin{tabular}{lllll}
\hline Thirds & GF/SA & GF/SE & $F R C / S A$ & $F R C / S E$ \\
\hline Cervical & $14.32 \pm 2.84^{\mathrm{a}, \mathrm{AC}}$ & $11.56 \pm 4.13^{\mathrm{a}, \mathrm{B}}$ & $16.89 \pm 2.66^{\mathrm{a}, \mathrm{A}}$ & $13.69 \pm 3.26^{\mathrm{a}, \mathrm{C}}$ \\
Middle & $10.69 \pm 2.72^{\mathrm{b}, \mathrm{AC}}$ & $6.49 \pm 2.54^{\mathrm{b}, \mathrm{B}}$ & $13.18 \pm 2.19^{\mathrm{b}, \mathrm{A}}$ & $9.58 \pm 2.23^{\mathrm{b}, \mathrm{C}}$ \\
Apical & $6.77 \pm 2.17^{\mathrm{c}, \mathrm{AC}}$ & $3.60 \pm 1.29^{\mathrm{c}, \mathrm{B}}$ & $8.45 \pm 1.77^{\mathrm{c}, \mathrm{A}}$ & $5.62 \pm 2.12^{\mathrm{c}, \mathrm{BC}}$ \\
\hline
\end{tabular}

*Different letters, lowercase in columns and uppercase in rows, indicate statistical difference between the values; SD: Standard deviation

obtained for the cervical, middle, and apical regions for experimental groups are displayed in Table 4.

The difference among the regions was statistically significant for all groups ( $p<0.05)$. For all groups, the bond strength was statistically higher $(p<0.05)$ in the cervical third. The self-adhesive resin cement showed better results than the self-etching resin cement when compared to each post ( $\mathrm{p}<0.05)$. No statistically significant differences in bond strengths of the resin cements existed after comparing each post ( $p>0.05)$.

Analyses of the specimens under stereomicroscope are displayed in Figures 2A to C. A prevalence of adhesive failures between cement and dentin were found (Table 5). The failures mode observed were similar among the specimens tested for regions.
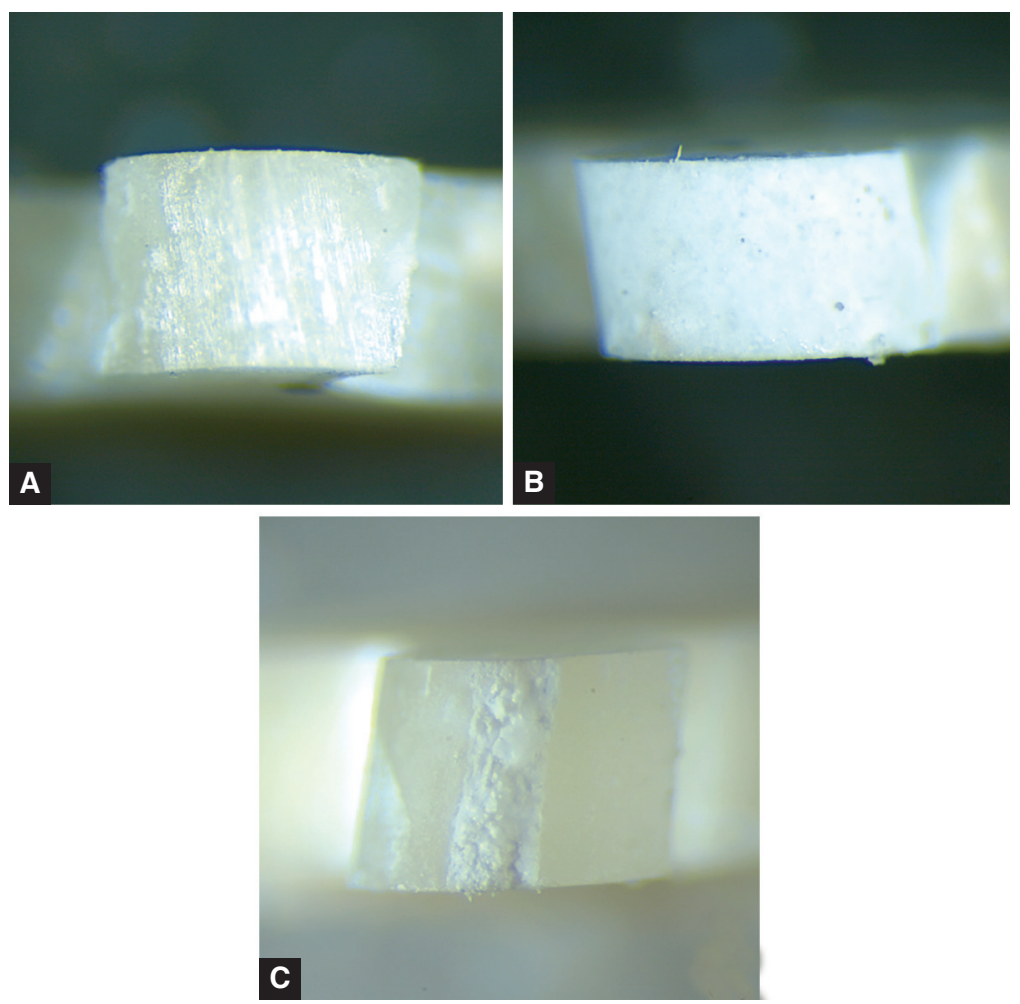

Figs 2A to C: The failure modes were found in this study: $(A)$ adhesion between post and resin cement, (B) adhesion between resin cement and root canal, and $(C)$ mixed with resin cement visible around the post
Scanning electron microscope evaluation revealed a good adaptation of the resin cement to the post interfaces for all groups (Figs 3A to D). No defects or discontinuations occurred along the interfaces, and no significant differences in the morphology of the interface between these groups were noticed.

\section{DISCUSSION}

The data of the present study supports the hypothesis that bond strength does vary among the regions. The bond strength is higher in the cervical region compared to the apical region. Nevertheless, the hypotheses were that bond strength did not vary among the fiber posts and that bond strength did vary among the resin cement systems. 
The Effect of Self-adhesive and Self-etching Resin Cements on the Bond Strength of Nonmetallic Posts

\begin{tabular}{lllll}
\hline & & Table 5: Distribution of failure modes among groups \\
\hline Groups & Thirds & Adhesive: cement dentin & Mixed & Adhesive: Cohesive in dentin Post-cement \\
\hline GF/SA & Cervical & 19 & & 1 \\
& Middle & 17 & 2 & 1 \\
& Apical & 15 & 3 & 2 \\
GF/SE & Cervical & 15 & 2 & 3 \\
& Middle & 16 & 3 & 1 \\
FRC/SA & Apical & 14 & 3 & 3 \\
& Cervical & 18 & & 2 \\
FRC/SE & Middle & 18 & 2 & 0 \\
& Apical & 15 & 3 & 2 \\
& Cervical & 16 & 2 & 2 \\
& Middle & 15 & 3 & 2 \\
& Apical & 15 & 3 & 2 \\
\hline
\end{tabular}

The root canals in the present study were filled with AH Plus and gutta-percha before the post space preparation, which is a more approximate clinical situation. Chieffi et $\mathrm{al}^{10}$ showed that resin sealer had no negative effect on the bond strength.

Several different laboratory assessments have been described for the evaluation of bond strength. The microtensile test places a uniform stress along the bonded interface due to the small specimen size. ${ }^{32}$ The stress distribution for pull-out and push-out tests had been reported as non-uniform when performed on root regions, $2,20,29,33,40$ and a major portion retention was created by the adhesive bonding agent and through

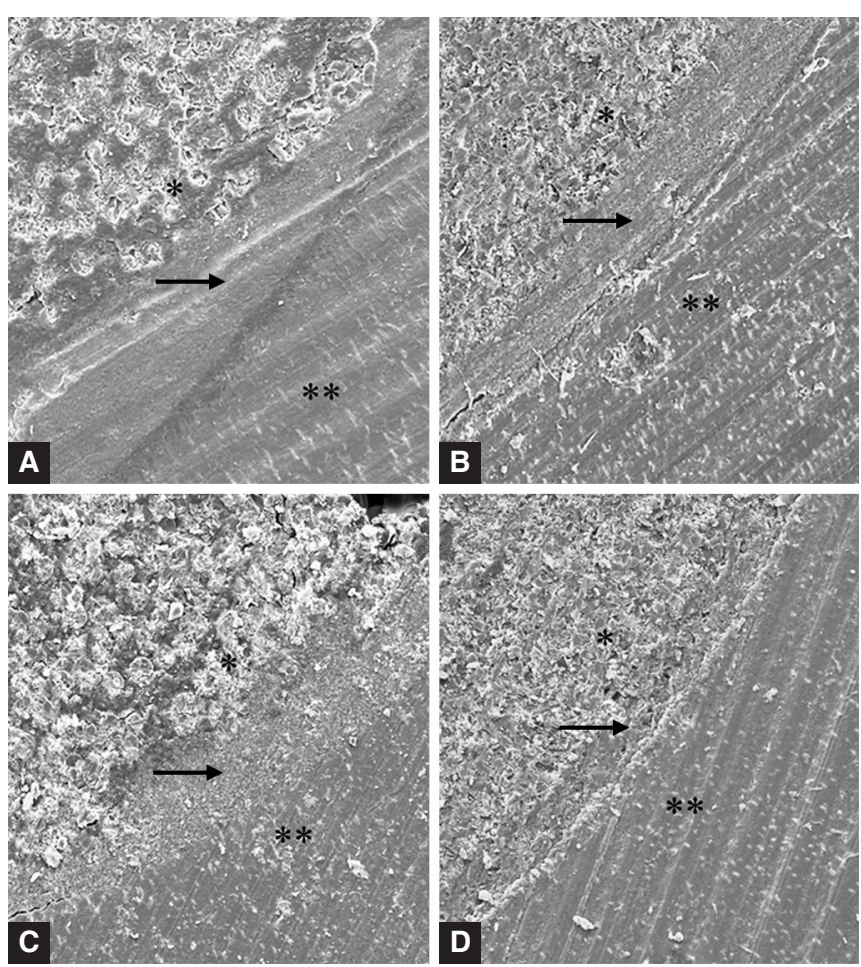

Figs $\mathbf{3 A}$ to D: Representative SEM micrographs of the resin dentin cement post interface: (A) EverStick post cemented with self-adhesive resin cement, (B) Exacto post cemented with self-adhesive resin cement, (C) EverStick post cemented with self-etching resin cement, and (D) Exacto post cemented with self-etching resin cement. ${ }^{*}$ post; ${ }^{* *}$ dentin root; $\rightarrow$ resin cement micro-retention from the surface roughness and macroretention from frictional fit between two surfaces. ${ }^{2}$ Thus, the microtensile test has become quite popular in dentin bond strength testing; however, the specimen preparation resulted in high rates of premature failures. ${ }^{2,20,21}$

The bond strength values were found to be significantly higher for all groups in the cervical region than in the middle and apical regions. Higher bond strength in the cervical region of the root canal was frequently shown in previous studies. ${ }^{8,23}$ This is to be expected because of the higher density of dentinal tubules and the area of a tubular dentine. ${ }^{16,17,42}$ The other factor is the more difficult access of the cervical to apical region and more difficulty in the distribution of resin cement with a void formation. ${ }^{8,25}$ Nevertheless, the polymerization contraction of the resin cement might have influenced the bond strength values. ${ }^{8}$

The bond strength values were found significantly higher for the self-adhesive resin cements than for the self-etching resin cement, irrespective of the type of fiber post used. No study has investigated the bond strength of fiber posts in conjunction with the resin cements used in this present study. Some researchers showed that the self-adhesive resin cements had better results on bond strength than other resin cements. 5,13,24,38 The composition of the self-adhesive resin cement favors good performance, because it exhibits a greater moisture tolerance than self-etching resin cements (sensitive technique). After rinsing the root canal, it is difficult to control the moisture because the visibility is poor. These findings can be explained through the pattern fractures that occurred during the microtensile bond strength test. The failure most often occurred at the interface between the resin cement and the dentin. Other adhesive failures occurred between posts and cement. Various pretreatment procedures were reported for increasing the bond strength of the post to the resin cement, as well as silanization, hydrofluoric acid etching, sandblasting, and tribochemical silica coating. ${ }^{6,9,30,43}$ 
Fiber-reinforced composite posts are made of a material with silanted glass fibers impregnated with an interpenetrating polymer network resin matrix partially based on polymethylmethacrylate resin (Everstick Post). The ability of the bonding resins to penetrate into the FRC post may provide the opportunity to improve the bond strength of the FRC post to resin cement. ${ }^{27}$ The design of the FRC post is also an important factor retention in the root canal. Parallel FRC posts have been shown to improve retention better than tapered posts. ${ }^{41}$ For this study, no significant difference was found between the posts studied, which corroborates the literature. ${ }^{1,45}$

\section{CONCLUSION}

The bond strength values were significantly affected by the resin cement and the highest values were found for self-adhesive resin cement. Fracture analysis showed a predominance of adhesive fractures between the resin cement and dentin.

\section{ACKNOWLEDGMENT}

The authors would like to thank FAPEMA and CAPES for financial support.

\section{REFERENCES}

1. Abo-Hamar SE, Hiller KA, Jung H, Federlin M, Friedl KH, Schmalz G. Bond strength of a new universal self-adhesive resin luting cement to dentin and enamel. Clin Oral Investig 2005;9:161-167.

2. Aksornmuang J, Foxton RM, Nakajima M, Tagami J. Microtensile bond strength of a dual-cure resin core material to glass and quartz fibre posts. J Dent 2004;32:443-450.

3. Alster D, Feilzer AJ, de Gee AJ, Davidson CL. Polymerization contraction stress in thin resin composite layers as a function of layer thickness. Dent Mater 1997;13:146-150.

4. Asmussen E, Peutzfeldt A, Heitmann T. Stiffness, elastic limit, and strength of newer types of endodontic posts. J Dent 1999;27:275-278

5. Bitter K, Meyer-Lueckel H, Priehn K, Kanjuparambil JP, Neumann K, Kielbassa AM. Effects of luting agent and thermocycling on bond strengths to root canal dentine. Int Endod J 2006;39:809-818.

6. Bitter K, Noetzel J, Neumann K, Kielbassa AM. Effect of silanization on bond strengths of fiber posts to various resin cements. Quintessence Int 2007;38:121-128.

7. Boschian Pest L, Cavalli G, Bertani P, Gagliani M. Adhesive post-endodontic restorations with fiber posts: push-out tests and SEM observations. Dent Mater 2002;18:596-602.

8. Bouillaguet S, Troesch S, Wataha JC, Krejci I, Meyer JM, Pashley DH. Microtensile bond strength between adhesive cements and root canal dentin. Dent Mater 2003;19:199-205.

9. Campos E, Calixto L, Bandeca M, Clavijo V, Andrade M, Vaz L. Effect of resin cement system and root region on the pushout bond strength of a translucent fiber post. Oper Dent 2011.

10. Chieffi N, Sadek F, Monticelli F, Goracci C, Grandini S, Davidson C, et al. Effect of dentin adhesives used as sealers and provisional cementation on bond strength of a resin cement to dentin. Am J Dent 2006;19:91-95.
11. De Munck J, Vargas M, Van Landuyt K, Hikita K, Lambrechts $\mathrm{P}$, Van Meerbeek B. Bonding of an auto-adhesive luting material to enamel and dentin. Dent Mater 2004;20:963-971.

12. Debnath S, Wunder SL, McCool JI, Baran GR. Silane treatment effects on glass/resin interfacial shear strengths. Dent Mater 2003;19:441-448.

13. Farina AP, Cecchin D, Garcia Lda F, Naves LZ, Pires-de-Souza Fde C. Bond strength of fibre glass and carbon fibre posts to the root canal walls using different resin cements. Aust Endod J 2011;37:44-50.

14. Feilzer AJ, de Gee AJ, Davidson CL. Setting stresses in composites for two different curing modes. Dent Mater 1993;9:2-5.

15. Feilzer AJ, De Gee AJ, Davidson CL. Setting stress in composite resin in relation to configuration of the restoration. J Dent Res 1987;66:1636-1639.

16. Ferrari M, Mannocci F. A 'one-bottle' adhesive system for bonding a fibre post into a root canal: an SEM evaluation of the post-resin interface. Int Endod J 2000;33:397-400.

17. Ferrari M, Mannocci F, Vichi A, Cagidiaco MC, Mjor IA. Bonding to root canal: structural characteristics of the substrate. Am J Dent 2000;13:255-260.

18. Gaston BA, West LA, Liewehr FR, Fernandes C, Pashley $\mathrm{DH}$. Evaluation of regional bond strength of resin cement to endodontic surfaces. J Endod 2001;27:321-324.

19. Goracci C, Cury AH, Cantoro A, Papacchini F, Tay FR, Ferrari $\mathrm{M}$. Microtensile bond strength and interfacial properties of self-etching and self-adhesive resin cements used to lute composite onlays under different seating forces. J Adhes Dent 2006;8:327-335.

20. Goracci C, Grandini S, Bossu M, Bertelli E, Ferrari M. Laboratory assessment of the retentive potential of adhesive posts: a review. J Dent 2007;35:827-835.

21. Goracci C, Tavares AU, Fabianelli A, Monticelli F, Raffaelli O, Cardoso PC, et al. The adhesion between fiber posts and root canal walls: comparison between microtensile and push-out bond strength measurements. Eur J Oral Sci 2004;112:353-361.

22. Hikita K, Van Meerbeek B, De Munck J, Ikeda T, Van Landuyt $\mathrm{K}$, Maida $\mathrm{T}$, et al. Bonding effectiveness of adhesive luting agents to enamel and dentin. Dent Mater 2007;23:71-80.

23. Kremeier K, Fasen L, Klaiber B, Hofmann N. Influence of endodontic post type (glass fiber, quartz fiber or gold) and luting material on push-out bond strength to dentin in vitro. Dent Mater 2008;24:660-666.

24. Leme A, Coutinho M, Insaurralde A, Scaffa P, da Silva L. The influence of time and cement type on push-out bond strength of fiber posts to root dentin. Oper Dent 2011;36:643-648.

25. Mallmann A, Jacques LB, Valandro LF, Mathias P, Muench A. Microtensile bond strength of light- and self-cured adhesive systems to intraradicular dentin using a translucent fiber post. Oper Dent 2005;30:500-506.

26. Mannocci F, Pilecki P, Bertelli E, Watson TF. Density of dentinal tubules affects the tensile strength of root dentin. Dent Mater 2004;20:293-296.

27. Mannocci F, Sherriff M, Watson TF, Vallittu PK. Penetration of bonding resins into fibre-reinforced composite posts: a confocal microscopic study. Int Endod J 2005;38:46-51.

28. Morris MD, Lee KW, Agee KA, Bouillaguet S, Pashley $\mathrm{DH}$. Effects of sodium hypochlorite and RC-prep on bond strengths of resin cement to endodontic surfaces. J Endod 2001;27:753-757.

29. Ngoh EC, Pashley DH, Loushine RJ, Weller RN, Kimbrough WF. Effects of eugenol on resin bond strengths to root canal dentin. J Endod 2001;27:411-414. 
30. Oliveira AS, Ramalho ES, Ogliari FA, Moraes RR. Bonding self-adhesive resin cements to glass fibre posts: to silanate or not silanate? Int Endod J 2011;44:759-763.

31. Omar H, El-Badrawy W, El-Mowafy O, Atta O, Saleem B. Microtensile bond strength of resin composite bonded to caries-affected dentin with three adhesives. Oper Dent 2007;32:24-30.

32. Pashley DH, Carvalho RM, Sano H, Nakajima M, Yoshiyama M, Shono Y, et al. The microtensile bond test: a review. J Adhes Dent 1999;1:299-309.

33. Patierno JM, Rueggeberg FA, Anderson RW, Weller RN, Pashley DH. Push-out strength and SEM evaluation of resin composite bonded to internal cervical dentin. Endod Dent Traumatol 1996;12:227-236.

34. Perdigao J, Gomes G, Lee IK. The effect of silane on the bond strengths of fiber posts. Dent Mater 2006;22:752-758.

35. Phrukkanon S, Burrow MF, Tyas MJ. The effect of dentine location and tubule orientation on the bond strengths between resin and dentine. J Dent 1999;27:265-274.

36. Proenca JP, Polido M, Osorio E, Erhardt MC, Aguilera FS, Garcia-Godoy F, et al. Dentin regional bond strength of self-etch and total-etch adhesive systems. Dent Mater 2007;23:1542-1548.

37. Schwartz RS, Robbins JW. Post placement and restoration of endodontically treated teeth: a literature review. J Endod 2004;30:289-301.
38. Soares CJ, Pereira JC, Valdivia AD, Novais VR, Meneses MS. Influence of resin cement and post configuration on bond strength to root dentine. Int Endod J 2011.

39. Sorensen JA, Martinoff JT. Intracoronal reinforcement and coronal coverage: a study of endodontically treated teeth. J Prosthet Dent 1984;51:780-784.

40. Sudsangiam S, van Noort R. Do dentin bond strength tests serve a useful purpose? J Adhes Dent 1999;1:57-67.

41. Teixeira EC, Teixeira FB, Piasick JR, Thompson JY. An in vitro assessment of prefabricated fiber post systems. J Am Dent Assoc 2006;137:1006-1012.

42. Vichi A, Grandini S, Davidson CL, Ferrari M. An SEM evaluation of several adhesive systems used for bonding fiber posts under clinical conditions. Dent Mater 2002;18: 495-502.

43. Wrbas KT, Altenburger MJ, Schirrmeister JF, Bitter K, Kielbassa AM. Effect of adhesive resin cements and post surface silanization on the bond strengths of adhesively inserted fiber posts. J Endod 2007;33:840-843.

44. Yang B, Ludwig K, Adelung R, Kern M. Micro-tensile bond strength of three luting resins to human regional dentin. Dent Mater 2006;22:45-56.

45. Zaitter S, Sousa-Neto MD, Roperto RC, Silva-Sousa YT, ElMowafy O. Microtensile bond strength of glass fiber posts cemented with self-adhesive and self-etching resin cements. J Adhes Dent 2011;13:55-59. 